\title{
Text Mining Approach to analyse the relation between obesity and breast cancer data
}

\author{
Dr. Ashok Kumar ${ }^{1, a}$, Priyanka Thakur ${ }^{1, b}$, Kanika Gupta ${ }^{1, \mathrm{c}}$ and Dr. Amit Pal ${ }^{2, \mathrm{~d}_{*}}$
}

Centre for Systems Biology and Bioinformatics, Panjab University, Chandigarh -160014, India ${ }^{1}$ Deptt. of Biochemistry, PGIMER, Chandigarh-160012, India ${ }^{2}$

\author{
E-mail address: ${ }^{a}$ ashokbiotech@gmail.com; \\ bptpriyanka010@gmail.com ${ }^{b}$ \\ 'guptakainka18@gmail.com ${ }^{c}$ \\ dmaximus1134@gmail.com*; dapal1134@gmail.com* \\ Corresponding Author: Dr. Amit Pal ${ }^{\mathrm{d} *}$
}

Keywords: BMI, Text mining, Obesity, Breast cancer

\begin{abstract}
Biomedical research needs to leverage and exploit large amount of information reported in scientific publication. Literature data collected from publications has to be managed to extract information, transforms into an understandable structure using text mining approaches. Text mining refers to the process of deriving high-quality information from text by finding relationships between entities which do not show direct associations. Therefore, as an example of this approach, we present the link between two diseases i.e. breast cancer and obesity.Obesity is known to be associated with cancer mortality, but little is known about the link between lifetime changes in BMI of obese person and cancer mortality in both males and females. In this article, literature data for obesity and breast cancer was obtained using PubMed database and then methodologies which employs groups of common genes and keywords with their frequency of occurrence in the data were used, aimed to establish relation between obesity and breast cancer visualized using Pi-charts and bar graphs. From the data analysis, we obtained 1 gene which showed the link between both the diseases and validated using statistical analysis and disease-connect web server. We also proposed 8 common higher frequency keywords which could be used for indexing while searching the literature for obesity and breast cancer in combination.
\end{abstract}

\section{INTRODUCTION}

The scientific literature provides a wealth of information to researchers. It may serve as a source of information that can be used for building research hypotheses that subsequently can be experimentally validated. This knowledgebase may serve as a source for interpretation of experimental results [1]. Current biomedical research needs to leverage and exploit the enormous amount of information reported in scientific publications. One of the most important entry points to scientific literature sources for biomedical research is PubMed. Now-a-days, text is the most common vehicle for the formal exchange of information. Text mining refers to the process of deriving high-quality information from text by finding relationships between entities which do not show direct associations. This approach uses the automated methods for exploiting the enormous amount of knowledge available in text documents [2]. It is used to identify different relations like gene-disease, drug-disease [3] and drug-target associations etc. [4]. Large-scale extraction and analysis of gene-disease associations, and integration with current biomedical knowledge, provided insights of information, found in the literature, and raised challenges regarding data prioritization and curation [5]. We will be using text data from obesity and breast cancer for this current project. Obesity defined as it is an abnormal accumulation of body fat. Obesity is major risk factors for a number of chronic diseases, cardiovascular diseases and cancer. Breast cancer is a kind of cancer that develops from breast cells. Obesity is known to be associated with cancer mortality, but little is known about the link between lifetime changes in BMI of obese person and cancer mortality in both males and females. Numerous epidemiological studies have reported a possible differential impact of BMI on breast cancer risk in women of various life stages[6].Conversely, there is statistically 
significant positive association between body weight and breast cancer risk among postmenopausal women[7].Our approach, particular aimed to establish relationships between entities. Software's have been used to execute relation between obesity and breast cancer on the basis of co-occurrence of common keywords and genes. We have taken obesity (group I), breast cancer (group II), obesity and breast cancer (group III) as our query. Literature data will be obtained from PubMed database. Keywords and genes with their frequency of occurrence will be extracted from the data using RapidMiner [8], Coremine and Pubmed.mineR [9]. Keywords and genes corresponds to higher frequency of occurrence will be selected and visualized in WordCloud [13]. Relative frequencies of co-occurrence of selected keywords will be obtained using PubMatrix [10].Gene Ontology of selected genes will be analyzed using Gene Ontology Consortium [11]. In the analysis of selected data for three groups, common genes and keywords will be selected. Co-occurrence of both the genes and keywords would be analyzed using PubMatrix. Validation of the final result will be done using Disease-connect [12].

\section{METHODOLOGY}

Dataselection. Literature data is obtained using PubMed database for 3 main groups that is group I as Obesity, group II as Breast Cancer, and group III as obesity and breast cancer in combination. Data was obtained by applying filter of text availability as 'Abstracts' and publication date as '5years'.

Mining of data. Three softwares are used to extract keywords and genes from the data. Keywords are extracted using RapidMiner and Coremine. RapidMiner is stand-alone software which is used to retrieve keywords with their frequency of occurrence in the literature data for all the three groups. Coremine is a web based search engine. Keywords are extracted from disease literature. Coremine gave keywords with their frequency of occurrence in NCBI for both the queries obesity and breast cancer but not for group III. From literature data, genes are extracted using Pubmed.mineR. It uses $\mathrm{R}$ package. List of number of genes with their frequency of occurrence in the data is obtained

Data analysis. Data obtained from 3 softwares then analyzed using spreadsheets in Ms-Excel and visualized in the form of Pi charts and Bar graphs. Highly frequent keywords and genes then selected from the data for further procedure. WordCloud: The WordCloud is a Cytoscape plugin generates a visual summary of these annotations by displaying them as a tag cloud, where more frequent words are displayed using a larger font size (5). Highly frequent keywords are visualized using WordCloud which shows the words connected with their frequency of occurrence in the data.PubMatrix: PubMatrix is a web-based tool that allows simple text based mining of the NCBI literature search service PubMed using any two lists of keywords terms, resulting in a frequency matrix of term co-occurrence (2). It is used to relate the keywords of 1 group with another. Cooccurrence of keywords in two groups is obtained.

From the results of PubMatrix 8 common highly frequent keywords then selected for further procedure.

Data enrichment. Data enrichment of selected genes with high frequency then done by using Gene Ontology Consortium. By comparing the gene ontologies of selected genes of all the three groups, 3 common genes then selected.

Co-occurrence of keywords and genes. PubMatrix is used to obtain co-occurrence between the selected 3 genes and 8 keywords. It is used to relate genes with keywords and their frequency of occurrence together

Validation. Final results obtained then validated using Disease-Connect web server which is the first public web server integrates comprehensive-omics and literature data, including a large amount of gene expression data, GenomeWide Association Studies catalog, and text-mined knowledge, to discover disease-disease connectivity via common molecular mechanisms (3). 


\section{RESULTS AND DISCUSSION}

Literature data from pubmed. Literature data is retrieved using PubMed database for group I(obesity),group II(breast cancer), group III(obesity and breast cancer) with applying filter of Text Availability as 'Abstracts' and Publication dates as '5 years'. Total 76776, 76487, 1212 results were obtained for group I, II and III, respectively.

Rapidminer to extract keywords. RapidMiner converts the literature data into the list of keywords corresponds to their frequency of occurrence in the data. Results obtained as attribute name,total occurrences, document occurrences and occurrence of words. List of total 43763, 107913, 33206 keywords were obtained for groups I, II and III respectively.

Coremine to extract keywords. Coremine extract keywords from medical literature. Coremine was used to decrease the redundancy of results of RapidMiner and to avoid the biasness. Total 9 and 11 keywords were obtained with their frequency of occurrence for group I and II respectively.

From the results of RapidMiner and Coremine 26,25and 8 keywords were selected on the basis of their higher frequency for group I, group II and Group III data, respectively.

Table1. Result of three softwares for all the groups

\begin{tabular}{|c|c|c|c|}
\hline Groups & PubMed & RapidMiner & Coremine \\
\hline Group I & 76776 papers & 43763 keywords & 9 keywords \\
\hline Group II & 76487 papers & 107913 keywords & 11 keywords \\
\hline Group III & 1212 papers & 33206 keywords & No result \\
\hline
\end{tabular}

Data visualization using WordCloud. Selected data for all the three groups then visualized using WordCloud plugin of Cytoscape. Figure 1, 2 and 3 shows network view, preferred layout view and in dock window, respectively.

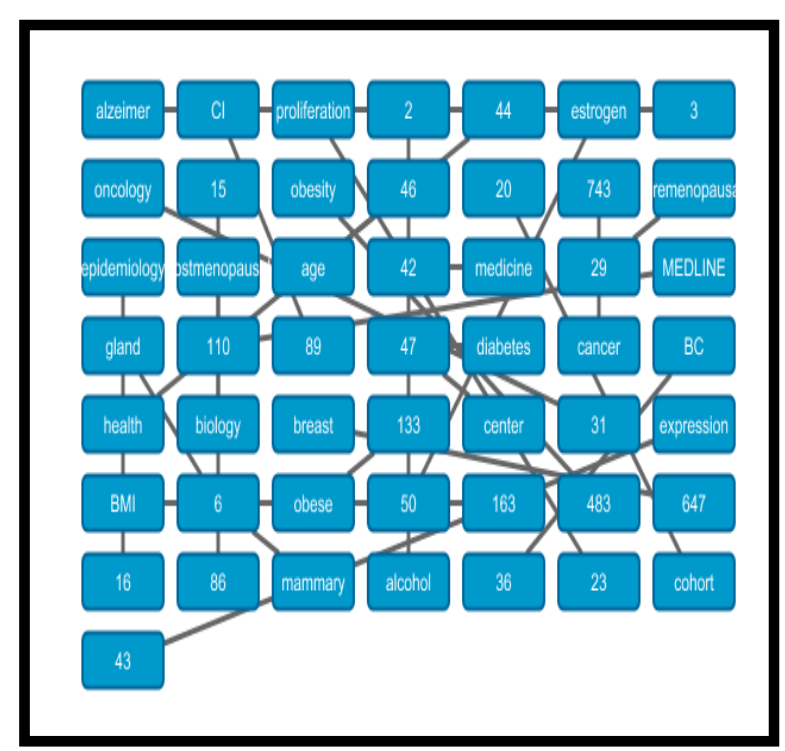

Figure 1: Network view

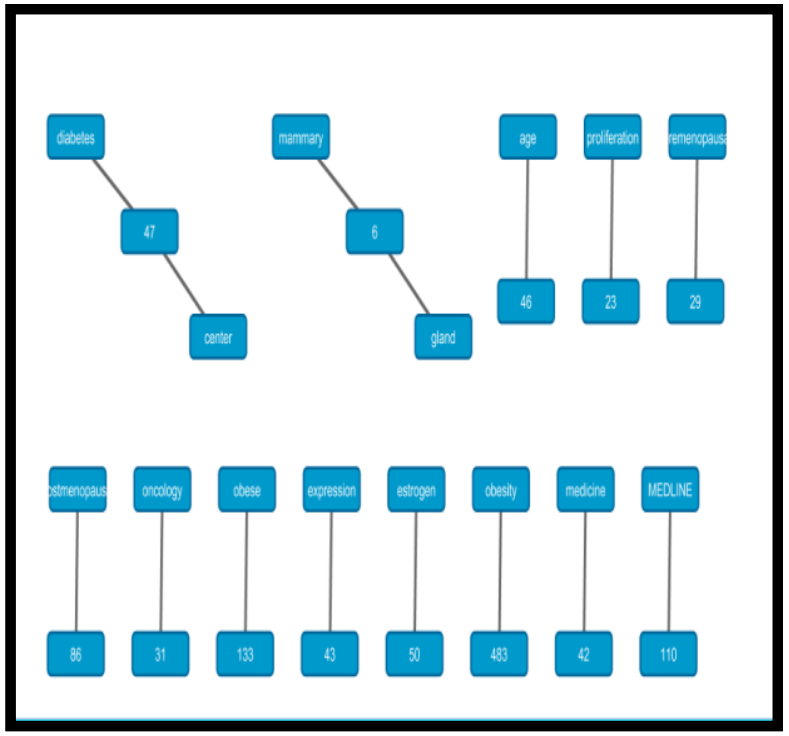

Figure 2: Preferred layout 


\section{postmenopausal obesity age}

diabetes premenopausal

mammary medline oncology

obese gland medicine center

alzeimer proliferation expression

estrogen bc alcohol

Figure 3: Visualization of selected keywords in dock window

Co-occurrence of keywords using pubmatrix. Selected keywords from RapidMiner and Coremine, considered as input for PubMatrix which analyze the co-occurrence of keywords in the form of matrix. Matrix is formed by pairwise comparison of each SEARCH TERM against each MODIFIER TERM. Frequency number in the table demonstrates the co-occurrence of both the keywords together.

Table 2: Matrix table shows frequency of co-occurrence of keywords of group I data with group III data

\begin{tabular}{|l|c|c|c|c|c|c|c|c|}
\hline Breast cancer & \multicolumn{7}{|c|}{ Obesity and breast cancer } \\
& Age & BMI & BRCA & Estrogen & $\begin{array}{c}\text { Post } \\
\text { menopausal }\end{array}$ & Adult & Proliferation & Prognostic \\
\hline & 70760 & 4556 & 28 & 6918 & 212 & 207622 & 10231 & 2290 \\
\hline Alcohol & 5035 & 292 & 83 & 987 & 61 & 11261 & 1367 & 960 \\
\hline BC & 49827 & 85896 & 24 & 1768 & 392 & 58490 & 446 & 1224 \\
\hline BMI & 49194 & 1571 & 386 & 16810 & 253 & 104133 & 47365 & 8064 \\
\hline Biology & 54055 & 2520 & 1934 & 46307 & 1768 & 142981 & 23752 & 18026 \\
\hline Breast & 162882 & 13437 & 240 & 19150 & 840 & 402730 & 12847 & 17078 \\
\hline CI & 274134 & 9030 & 2476 & 71026 & 2626 & 1215148 & 166242 & 116523 \\
\hline Cancer & 263481 & 15637 & 706 & 24474 & 904 & 657064 & 63541 & 33401 \\
\hline Center & 148772 & 12898 & 265 & 5242 & 462 & 239601 & 2661 & 17686 \\
\hline Cohort & 507857 & 29677 & 513 & 15890 & 1347 & 936656 & 8373 & 64412 \\
\hline Epidemiology & 25181 & 386 & 20 & 12533 & 134 & 87313 & 11078 & 2098 \\
\hline Gland & 457089 & 33092 & 561 & 24402 & 1814 & 949263 & 29757 & 18542 \\
\hline Health & 8385 & 445 & 29 & 820 & 83 & 13649 & 321 & 1352 \\
\hline MEDLINE & 57090 & 2552 & 1937 & 49494 & 1778 & 149507 & 26616 & 18245 \\
\hline Mammary & 413007 & 26643 & 593 & 37362 & 1679 & 1131726 & 99657 & 46567 \\
\hline Medicine & 58126 & 38366 & 13 & 3470 & 476 & 96256 & 2209 & 1291 \\
\hline Obesity & 29278 & 1768 & 229 & 224654 & 2925 & 72015 & 14169 & 6399 \\
\hline Estrogen & 78282 & 2566 & 441 & 42629 & 526 & 257065 & 172203 & 37972 \\
\hline Expression & 1883725 & 49827 & 615 & 29278 & 2685 & 1116442 & 18191 & 47808 \\
\hline Obese & 63683 & 41690 & 14 & 3865 & 523 & 104400 & 2619 & 1460 \\
\hline Oncology & 39569 & 1199 & 625 & 7867 & 324 & 118503 & 18813 & 25548 \\
\hline Postmenopausal & 15670 & 2162 & 32 & 20200 & 2074 & 33833 & 1166 & 800 \\
\hline Premenopausal & 6149 & 1059 & 36 & 4784 & 704 & 11479 & 362 & 518 \\
\hline Proliferation & 18191 & 446 & 106 & 14169 & 229 & 68513 & 406446 & 8278 \\
\hline Age & 20120 & 9 & 3833 & 359 & 217891 & 8190 & 4899 \\
\hline Diabetes & 110707 & & & & \\
\hline & & & & & & \\
\hline
\end{tabular}


Table 3: Matrix table shows frequency of co-occurrence of keywords of group II data with group III data

\begin{tabular}{|l|r|r|r|r|r|r|r|r|}
\hline \multicolumn{1}{|c|}{ Obesity } & \multicolumn{7}{|c|}{ Breast cancer and obesity } \\
\hline & Age & BMI & BRCA & Estrogen & $\begin{array}{c}\text { Post } \\
\text { menopausal }\end{array}$ & Adult & Proliferation & Prognostic \\
\hline AR & 13179 & 827 & 15 & 3556 & 96 & 29011 & 7264 & 853 \\
\hline Abdominal & 47590 & 5764 & 30 & 2252 & 269 & 176376 & 3530 & 3852 \\
\hline Active & 58938 & 2907 & 52 & 9104 & 307 & 165774 & 25586 & 4088 \\
\hline Adult & 1116442 & 58490 & 1081 & 72015 & 5206 & 6047184 & 68513 & 112164 \\
\hline Age & 1883725 & 49827 & 615 & 29278 & 2685 & 1116442 & 18191 & 47808 \\
\hline Alcohol & 70760 & 4556 & 28 & 6918 & 212 & 207622 & 10231 & 2290 \\
\hline Alzeimer & 0 & 0 & 0 & 0 & 0 & 0 & 0 & 0 \\
\hline Appetite & 3717 & 1337 & 1 & 296 & 17 & 10604 & 198 & 151 \\
\hline Asthma & 21206 & 887 & 0 & 316 & 16 & 53976 & 2116 & 389 \\
\hline BC & 5035 & 292 & 83 & 987 & 61 & 11261 & 1367 & 960 \\
\hline BMI & 49827 & 85896 & 24 & 1768 & 392 & 58490 & 446 & 1224 \\
\hline BRCA & 615 & 24 & 2590 & 229 & 10 & 1081 & 106 & 93 \\
\hline Baseline & 90612 & 10867 & 50 & 6127 & 699 & 222804 & 2826 & 8304 \\
\hline Biological & 135112 & 7544 & 571 & 36263 & 922 & 347902 & 98893 & 38993 \\
\hline Blood & 401828 & 33848 & 184 & 58599 & 2309 & 1315430 & 102927 & 43961 \\
\hline Brain & 152043 & 2130 & 23 & 22210 & 270 & 440339 & 26222 & 12290 \\
\hline Breast & 54055 & 2520 & 1934 & 46307 & 1768 & 142981 & 23752 & 18026 \\
\hline Cancer & 274134 & 9030 & 2476 & 71026 & 2626 & 1215148 & 166242 & 116523 \\
\hline CI & 162882 & 13437 & 240 & 19150 & 840 & 402730 & 12847 & 17078 \\
\hline Cohort & 148772 & 12898 & 265 & 5242 & 462 & 239601 & 2661 & 17686 \\
\hline Agriculture & 10116 & 296 & 1 & 1377 & 14 & 11587 & 1993 & 46 \\
\hline Obesity & 58126 & 38366 & 13 & 3470 & 476 & 96256 & 2209 & 1291 \\
\hline Oncology & 39569 & 1199 & 625 & 7867 & 324 & 118503 & 18813 & 25548 \\
\hline Estrogen & 29278 & 1768 & 229 & 224654 & 2925 & 72015 & 14169 & 6399 \\
\hline Postmenopausal & 15670 & 2162 & 32 & 20200 & 2074 & 33833 & 1166 & 800 \\
\hline Diabetes & 110707 & 20120 & 9 & 3833 & 359 & 217891 & 8190 & 4899 \\
\hline Women & 277764 & 25806 & 1014 & 48734 & 5798 & 487368 & 5798 & 11007 \\
\hline
\end{tabular}

By comparing the data of group I, group II and group III using outputs of RapidMiner, Coremine and PubMtarix, 8 common keywords were extracted. These 8 common were selected on the basis of their higher frequency of occurrence and co-occurrence in the data.

Pubmed.miner to extract genes. Pubmed.mineR extract genes form the literature data. Pubmed.mineR gave result as total number of genes with their frequency of occurrence in the literature data. Total 979, 4449, 1849 genes with their frequency of occurrence is obtained for group I,II and III.

Data enrichment using gene ontology consortium. Gene ontology for selected genes of all the three data was obtained.

\begin{tabular}{|c|c|c|c|c|c|c|}
\hline $\begin{array}{l}\text { SR. } \\
\text { NO }\end{array}$ & Gene ID & $\begin{array}{l}\text { Mapped } \\
\text { ID's }\end{array}$ & Gene name & $\begin{array}{l}\text { Gene } \\
\text { symbol }\end{array}$ & PANTHER protein class & Species \\
\hline 1 & $\mathrm{HGNC}=9582$ & PTEN & $\begin{array}{l}\text { Dual-specificity } \\
\text { protein } \\
\text { phosphatase PTEN }\end{array}$ & PTEN & protein phosphatase & Homo Sapiens \\
\hline 2 & $\mathrm{HGNC}=1100$ & BRCA1 & $\begin{array}{l}\text { Breast cancer type } \\
1 \text { susceptibility } \\
\text { protein }\end{array}$ & BRCA1 & ubiquitin protein ligase & Homo Sapiens \\
\hline 3 & $\mathrm{HGNC}=11089$ & SLN & Sarcolipin & SLN & - & Homo Sapiens \\
\hline 4 & $\mathrm{HGNC}=3236$ & EGFR & $\begin{array}{l}\text { Epidermal growth } \\
\text { factor receptor }\end{array}$ & EGFR & - & Homo Sapiens \\
\hline 5 & HGNC=11515 & $\mathrm{T}$ & Brachyury protein & $\mathrm{T}$ & $\begin{array}{l}\text { transcription factor nucleic } \\
\text { acid binding }\end{array}$ & Homo Sapiens \\
\hline 6 & $\mathrm{HGNC}=1101$ & BRCA2 & $\begin{array}{l}\text { Breast cancer type } 2 \\
\text { susceptibility protein }\end{array}$ & BRCA2 & $\begin{array}{l}\text { damaged DNA binding } \\
\text { protein }\end{array}$ & Homo Sapiens \\
\hline 7 & $\mathrm{HGNC}=644$ & AR & Androgen receptor & AR & $\begin{array}{l}\text { nuclear hormone receptor, } \\
\text { nucleic acid binding }\end{array}$ & Homo Sapiens \\
\hline 8 & $\mathrm{HGNC}=5172$ & $\mathrm{HR}$ & protein hairless & $\mathrm{HR}$ & $\begin{array}{l}\text { Zinc finger transcription } \\
\text { factor, nucleic acid binding }\end{array}$ & Homo Sapiens \\
\hline
\end{tabular}

Figure 3: Gene Ontology of selected genes of higher frequency from group I data 


\begin{tabular}{|c|c|c|c|c|c|c|}
\hline $\begin{array}{l}\text { SR. } \\
\text { NO }\end{array}$ & Gene ID & $\begin{array}{l}\text { Mapped } \\
\text { ID's }\end{array}$ & Gene Name & $\begin{array}{l}\text { Gene } \\
\text { Symbol }\end{array}$ & PANTHER Protein Class & Species \\
\hline 1 & $\mathrm{HGNC}=1424$ & CAD & CAD protein & CAD & Transferase, ligase & $\begin{array}{l}\text { Homo } \\
\text { Sapiens }\end{array}$ \\
\hline 2 & $\mathrm{HGNC}=3678$ & FGF21 & $\begin{array}{l}\text { Fibroblast growth factor } \\
21\end{array}$ & FGF21 & Growth factor & $\begin{array}{l}\text { Homo } \\
\text { Sapiens }\end{array}$ \\
\hline 3 & $\mathrm{HGNC}=24678$ & F10 & $\begin{array}{l}\text { Alpha-ketoglutarate } \\
\text { dependent dioxygenase } \\
\text { FTO }\end{array}$ & F10 & - & $\begin{array}{l}\text { Homo } \\
\text { Sapiens }\end{array}$ \\
\hline 4 & $\mathrm{HGNC}=11764$ & TG & Thyroglobulin & TG & Esterase, lipase & $\begin{array}{l}\text { Homo } \\
\text { Sapiens }\end{array}$ \\
\hline 5 & $\mathrm{HGNC}=11316$ & SSB & Lupus la protein & SSB & Ribonucleoprotein & $\begin{array}{l}\text { Homo } \\
\text { Sapiens }\end{array}$ \\
\hline 6 & HGNC=11515 & T & Brachyury protein & T & $\begin{array}{l}\text { Transcription factor, nucleic } \\
\text { acid binding }\end{array}$ & $\begin{array}{l}\text { Homo } \\
\text { Sapiens }\end{array}$ \\
\hline 7 & $\mathrm{HGNC}=2367$ & CRP & C-reactive protein & CRP & $\begin{array}{l}\text { Antibacterial response } \\
\text { protein }\end{array}$ & $\begin{array}{l}\text { Homo } \\
\text { Sapiens }\end{array}$ \\
\hline 8 & $\mathrm{HGNC}=6932$ & MC4R & Melanocortin receptor 4 & MC4R & G-protein coupled receptor & $\begin{array}{l}\text { Homo } \\
\text { Sapiens }\end{array}$ \\
\hline 9 & $\mathrm{HGNC}=644$ & AR & Androgen receptor & AR & $\begin{array}{l}\text { Nuclear hormone receptor, } \\
\text { nucleic acid binding }\end{array}$ & $\begin{array}{l}\text { Homo } \\
\text { Sapiens }\end{array}$ \\
\hline 10 & $\mathrm{HGNC}=5172$ & HR & Protein hairless & HR & $\begin{array}{l}\text { Zinc finger transcription } \\
\text { factor, nucleic acid binding }\end{array}$ & $\begin{array}{l}\text { Homo } \\
\text { Sapiens }\end{array}$ \\
\hline
\end{tabular}

Figure 4: Gene Ontology of selected genes of higher frequency from group II data

Correlation between genes and keywords using pubmtarix. 3 common genes and 8 common keywords were selected from previous results. Correlation between genes and keywords was checked using Pubmatrix.

Table 4: Matrix table showing co-occurrence of genes with keywords

\begin{tabular}{|l|r|r|r|}
\hline \multirow{2}{*}{ Keywords } & \multicolumn{3}{|c|}{ Genes } \\
\cline { 2 - 4 } & \multicolumn{1}{|c|}{ HR } & \multicolumn{1}{c|}{ AR } & \multicolumn{1}{c|}{ T } \\
\hline Age & 29649 & 13183 & 1 \\
\hline BMI & 2275 & 827 & 0 \\
\hline Estrogen & 3375 & 3556 & 0 \\
\hline Postmenopausal & 1046 & 997 & 0 \\
\hline Proliferation & 4498 & 7266 & 0 \\
\hline Cancer & 32963 & 15289 & 0 \\
\hline Diabetes & 6981 & 2728 & 0 \\
\hline Breast & 5256 & 2045 & 0 \\
\hline
\end{tabular}

Table 4 shows the probability of occurrence of keywords and genes together. Genes AR and HR show higher frequency of co-occurrence with all the keywords but Gene $\mathrm{T}$ shows its frequency of co-occurrence only with the keyword Age. This shows that genes AR and HR relate the diseases, obesity and breast cancer with each other. 
Validation using disease-connect web server.

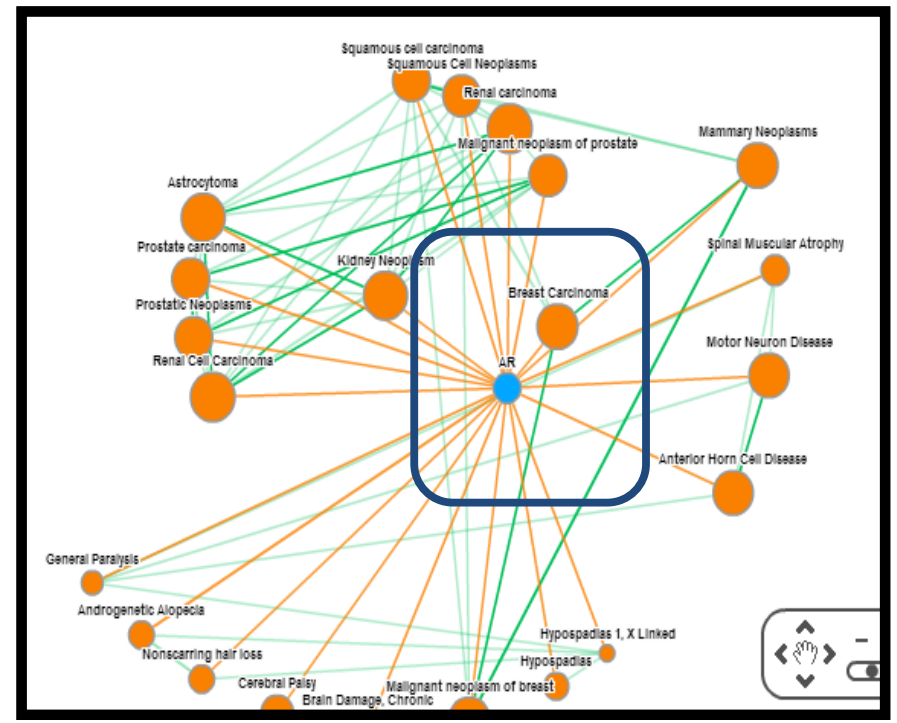

Figure 5: Network of Disease associated with Gene AR

Gene AR when searched for associated disease network, then Breast Carcinoma was associated with the gene. Network shows the diseases associated with $\underline{\mathbf{A R}}$ based on the GWAS/OMIM/DEG records.

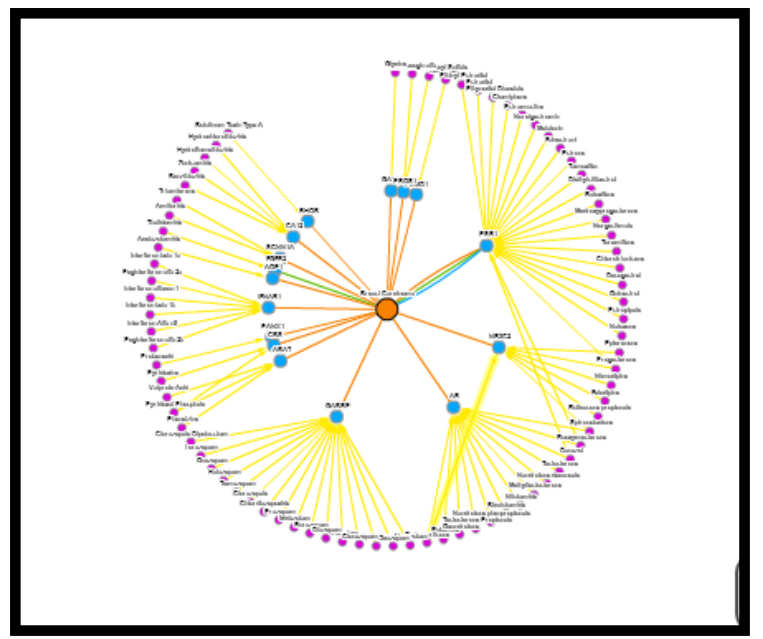

Figure 6: Disease-gene-drug network

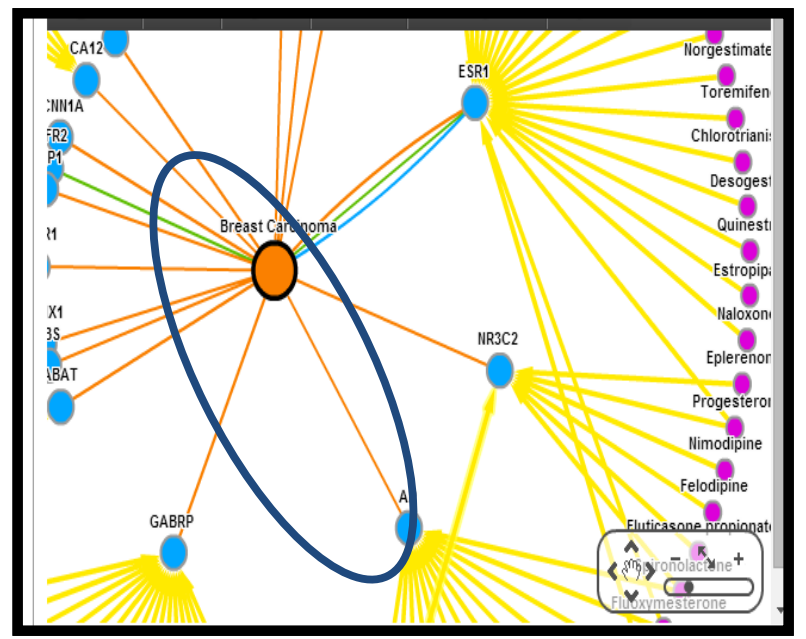

Figure 7: Disease-gene network

Figure 6 shows the disease-gene-drug network contains genes related to Breast Carcinoma based on the GWAS/OMIM/DEG records. Figure 7 shows the presence of AR gene in the disease gene network of breast Carcinoma. 


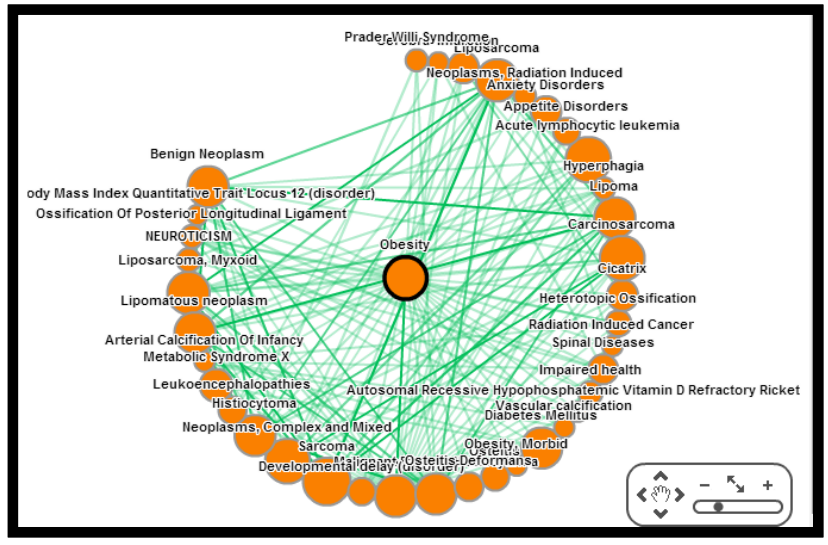

Figure 8: Network shows the disease

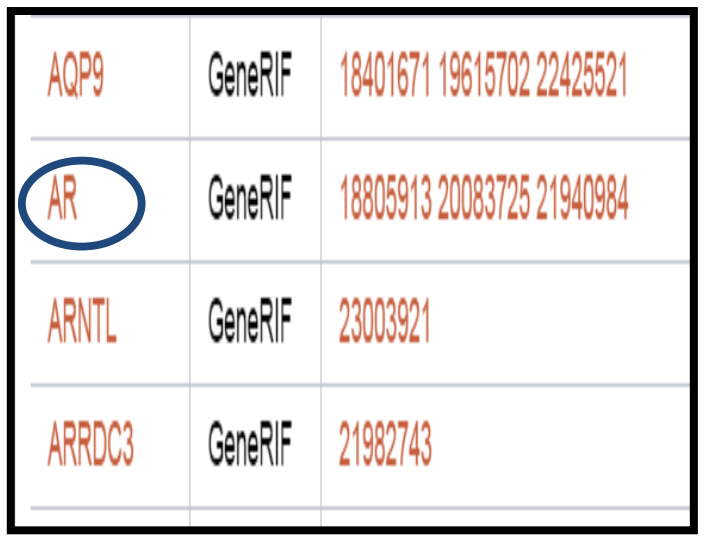

Figure 9: Genes Associated with Obesity

Figure 8 shows disease associated with obesity. Figure 9 shows the Genes that are relevant to Obesity based on the GeneRIF (Gene Reference into Function) and GeneWays records. GeneWays provides disease-gene relations extracted from full-text articles and abstracts in PubMed.

\section{CONCLUSION}

Obesity has differential effect on breast cancer risk in women of various life stages. Text mining approach was used to reveal the relationship between both the diseases on the basis of cooccurrence of molecular markers and keywords. On the basis of text mining procedure in present study it is concluded that AR gene could be potentially linked between obesity and breast cancer. The frequency of selective keywords demonstrates the linking between both the diseases and these words could be used for indexing while searching the literature for obesity and breast cancer in combination.

\section{Acknowledgement}

Authors are thankful to Vice Chancellor of Panjab University, Chandigarh and coordinator of Centre for Systems biology and bioinformatics for providing all the facilities to carry out this work. We would also like to acknowledge the support provided by online tools, servers, databases and softwares for successful accomplishment of our work that is PubMed Database (http://www.ncbi.nlm.nih.gov/pubmed), Rapid Miner (https://rapidminer.com/products/studio/), Coremine (http://www.coremine.com/medical/), Pubmed.mineR (https://cran.rproject.org/web/packages/pubmed.mineR/index.html),

(http://baderlab.org/Software/WordCloudPlugin), Gene Ontology Consortium (http://geneontology.org/), DiseaseConnect (http://disease-connect.org/).

\section{References}

[1] Funk, C. S., I. Kahanda, A. Ben-Hur and K. M. Verspoor (2015). "Evaluating a variety of text-mined features for automatic protein function prediction with GOstruct." J Biomed Semantics6: 9.

[2] Preiss, J., M. Stevenson and R. Gaizauskas (2015). "Exploring Relation Types for Literaturebased Discovery." J Am Med Inform Assoc.

[3] Ramezankhani, A., O. Pournik, J. Shahrabi, F. Azizi and F. Hadaegh (2015). "An application of association rule mining to extract risk pattern for type 2 diabetes using tehran lipid and glucose study database." Int J Endocrinol Metab13(2): e25389.

[4] Burkhart, K. K., D. Abernethy and D. Jackson (2015). "Data Mining FAERS to Analyze Molecular Targets of Drugs Highly Associated with Stevens-Johnson Syndrome." J Med Toxicol. 
[5] Bravo, A., J. Pinero, N. Queralt-Rosinach, M. Rautschka and L. I. Furlong (2015). "Extraction of relations between genes and diseases from text and large-scale data analysis: implications for translational research." BMC Bioinformatics16(1): 55.

[6] Taghizadeh, N., H. M. Boezen, J. P. Schouten, C. P. Schroder, E. G. Vries and J. M. Vonk (2015). "BMI and Lifetime Changes in BMI and Cancer Mortality Risk." PLoS One10(4): e0125261.

[7] Scholz, C., U. Andergassen, P. Hepp, C. Schindlbeck, T. W. Friedl, N. Harbeck, M. Kiechle, H. Sommer, H. Hauner, K. Friese, B. Rack and W. Janni (2015). "Obesity as an independent risk factor for decreased survival in node-positive high-risk breast cancer." Breast Cancer Res Treat.

[8] "Rapid-I: Rapid Miner." Rapid - I. Rapid - I, n.d. Web. 10 Nov. 2012.

[9] Jyoti Rani, S.Ramachandan and Ab. Rauf Shah (2014). Text mining of PubMed abstracts. R package version 1.0.4.

[10] Kevin Becker, Douglas Hosack, Glynn Dennis, Richard A Lempicki, Tiffani J Bright ,Chris Cheadle and Jim Engel (10 December 2003), PubMatrix: atool for multiplex literature mining BMC Bioinformatics, Vol. 4, No. 161.

[11] Ashburner et al, Gene ontology: tool for the unification of biology (2000) Nat Genet 25(1):25-9

[12] Liu CC, Tseng YT, Li W, Wu CY, Mayzus I, Rzhetsky A, Sun F, Waterman M, Chen JJ, Chaudhary PM, Loscalzo J, Crandall E, Zhou XJ. (2014) DiseaseConnect: a comprehensive web server for mechanism-based disease-disease connections. Nucleic Acids Research.

[13] Layla Oesper, Daniele Merico, Ruth Isserlin and Gary D Bader (2011). WordCloud: a cytoscape plugin to create a visual semantic summary of networks. Source Code for Biology and Medicine, 6:7. 